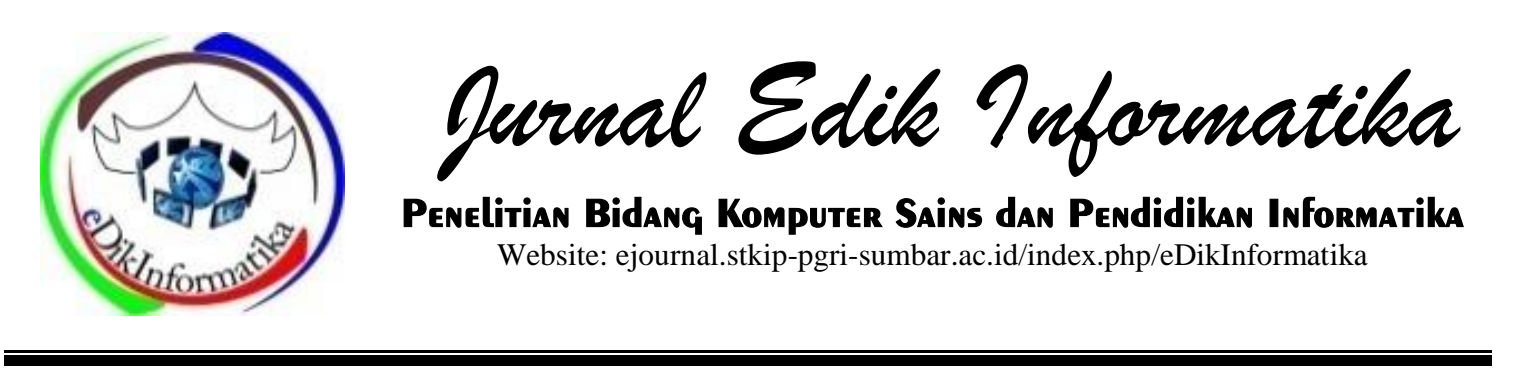

\title{
BLACK BOX TESTING BOUNDARY VALUE ANALYSIS PADA APLIKASI SUBMISSION SYSTEM
}

\author{
Luthfie Auditya Amarul Ma'ruf', Condro Kartiko², Citra Wiguna ${ }^{3}$ \\ ${ }^{1,2,3}$ Institut Teknologi Telkom Puwekerto \\ condro.kartiko@ittelkom-pwt.ac.id
}

\begin{tabular}{l} 
INFO ARTIKEL \\
\hline Diterima: \\
09 April 2020 \\
Direview: \\
16 April 2020 \\
Disetujui: \\
29 April 2020 \\
\hline
\end{tabular}

Keywords:

Submission System,

Website, Black Box

Testing, Boundary

Value Analysis

\begin{abstract}
Organizing a scientific conference activity is an opportunity for researchers to meet and share research or study that is being done. One of the most important parts of conducting a scientific conference is the process of submission and review paper sent by researchers. The process of using a submission system on a website requires many menus and features that must be available. However, in making a website there are often errors in the interface, submission system, task orientation, submit login, submit sign-up, writing, content quality, page layout, visual design, help and error tolerance. In the following research, applying to test using black-box testing boundary value analysis techniques. Boundary Value Analysis method is a way of testing by determining the value of the lower and upper limits of the data to be tested. This test is performed on the submission system function on the CENTIVE website. The test results show that there are still many shortcomings when validating data that will be input so that it can cause data stored in the database does not match the expected data. Test results can be used as input to improve the system.
\end{abstract}

\section{PENDAHULUAN}

Website merupakan kumpulan halaman-halaman yang saling terhubung yang berguna menampilkan informasi berupa teks, gambar, animasi, suara dan gabungan dari semuanya sehingga membentuk serangkaian yang saling berkaitan. Pada kemampuan ini, website menjadi sangat terkenal dan berkembang sangat pesat sehingga banyak digunakan pada berbagai bidang, salah satunya bidang akademik.

Institut Teknologi Telkom Purwokerto yang merupakan salah satu institusi yang berada pada bidang akademik di Indonesia, memanfaatkan 
website untuk memberikan informasi mengenai seminar bertaraf nasional dan Call For Papers (CFP) yang dinamakan CENTIVE. Kegiatan CENTIVE merupakan penyelenggaraan suatu kegiatan konferensi ilmiah yang memberikan sebuah kesempatan bagi para peneliti untuk bertemu dan berbagi tentang penelitian atau studi yang sedang dikerjakan. Salah satu bagian terpenting dalam pelaksanaan konferensi ilmiah adalah proses submission dan review paper yang dikirimkan oleh peneliti. Proses penggunaan submission system pada website membutuhan banyak menu dan fitur yang harus tersedia. Namun, dalam membuat website sering terjadi kesalahan pada interface, submission system, task orientation, submit login, submit sign-up, writing, content quality, page-layout, visual design, help dan error tolerance (Prasetio, et al., 2014). Sistem CENTIVE memiliki banyak kekurangan dalam melakukan proses manajemen data, sehingga stakeholder kurang efektif dan efisien dalam memproses data pada submission system CENTIVE. Selain itu, pengelola sistem CENTIVE menyatakan bahwa masih ditemukan kesulitan dalam mencari solusi pada permasalahan yang terjadi ketika penggunaannya. Berdasarkan permasalahan tersebut dapat disimpulkan bahwa terjadi kesulitan memanajemen data paper yang akan di proses serta seluruh data pengguna yang ada pada sistem informasi CENTIVE sehingga dapat memperlambat proses kegiatan CENTIVE.

Pengembangan sistem dilakukan dengan menggunakan metode scrum. Prinsip yang digunakan dengan metode Scrum yaitu, perencanaan pembuatan sebuah tim, menentukan scrum master dan anggota untuk membagi tugas pada setiap anggota, back-log yang digunakan untuk mengevaluasi pengembangan yang akan dilakukan pada bagian bisnis yang terdapat pada sistem informasi, sprint yang akan digunakan untuk menentukan tahap-tahap proses pengembangan sistem (Stellman \& Hart, 2013).

Pengujian sistem berguna untuk verifikasi dan validasi kesesuaian dengan kebutuhan pengguna (Kartiko \& Hertantyo, Peningkatan Kualitas Aplikasi Pemantau Media Sosial dan Media Daring Menggunakan Metode WebQEM, 2018). Selain itu juga dapat meningkatkan kualitas perangkat lunak (Kartiko, 2019). Pada penelitian ini dicoba diterapkan pengujian dengan menggunakan teknik Black Box Testing. Metode Black Box Testing terdiri atas beberapa cara antara lain Equivalence Partitioning, Boundary Value Analysis, Comparison Testing, Sample Testing, Robustness Testing, dan lain-lain. Diantara sekian banyak cara pengujian tersebut, pada penelitian ini memilih cara pengujian Boundary Value Analysis (Sutanto et al. 2018).

Boundary Value Analysis merupakan cara pengujian dengan menentukan nilai batas bawah dan batas atas dari data yang ingin diuji. Pengujian ini dilakukan pada fungsi submission system website CENTIVE. Oleh karena itu dapat diketahui tingkat error yang terjadi setelah pengujian dilakukan dengan teknik Boundary Value Analysis.

Setelah sistem selesai dikembangkan, maka perlu dilakukan pengujian untuk memastikan semua proses berjalan sesuai dengan product backlog. Pengujian tersebut adalah suatu proses yang dilakukan pada suatu aplikasi atau sistem yang bertujuan untuk menemukan suatu kesalahan. Suatu kasus pengujian yang baik adalah apabila hasil pengujian tersebut mempunyai kemungkinan menemukan sebuah kesalahan yang tidak terungkap sebelumnya. Suatu pengujian yang sukses adalah bila pengujian tersebut 
membongkar suatu kesalahan yang awalnya tidak ditemukan. Tujuan utama dari pengujian adalah untuk mendesain pengujian yang secara sistematik menemukan jenis kesalahan dengan usaha dan waktu minimum.

\section{METODE}

\section{Black Box Testing}

Pengertian dari black box testing merupakan teknik pengujian yang berfokus pada spesifikasi fungsional dari perangkat lunak. Pengujian bekerja dengan mengabaikan struktur pada control sehingga berfokus pada informasi domain. Pengujian menggunakan black box testing memungkinkan pengembang sistem untuk membuat himpunan kondisi input yang akan melatih seluruh batasanbatasan fungsional pada suatu sistem (Jaya, 2018).

Keuntungan dalam menggunakan metode black box testing adalah pengujian tidak perlu memiliki pengetahuan tentang bahasa pemrograman tertentu. Pengujian dilakukan dari sudut pandang pengguna sehingga programmer dan tester keduanya saling bergantung satu sama lain (Hidayat \& Putri, 2019).

Kekurangan dari metode black box testing adalah pengujian kasus sulit didesain tanpa spesifikasi yang jelas. Memungkinkan memiliki pengulangan pengujian yang sudah dilakukan oleh developer. Beberapa bagian back end tidak diuji sama sekali.

Black box testing berfokus untuk menemukan hal-hal berikut (Nurudin et al, 2019):

1. Kesalahan antarmuka (interface errors).

2. Fungsi yang tidak benar atau tidak ada.
3. Kesalahan pada performasi (performance errors).

4. Kesalahan pada struktur data dan akses basis data.

Pengujian didesain untuk menjawab pertanyaan-pertanyaan berikut (Anardani \& Putera, 2019):

1. Bagaimana fungsi-fungsi diuji agar data dapat dinyatakan valid?

2. Input seperti apa yang dapat menjadi bahan kasus uji yang baik?

3. Apakah sistem sensitif pada data input tertentu?

\section{Boundary Value Analysis (BVA)}

Boundary value analysis merupakan salah satu teknik dalam metode pengujian black box yang fokus pada proses input dengan menguji nilai batas atas dan nilai batas bawah. Prinsip kerja BVA yaitu, kesalahan yang banyak terjadi adalah ketika proses input, BVA bekerja pada proses input (Ardana, 2019).

\section{HASIL DAN PEMBAHASAN}

Berdasarkan pada penjelasan sebelumnya, pengujian akan diterapkan teknik BVA untuk pengujian aplikasi yaitu submission system pada website CENTIVE. Pada penelitian yang dilakukan, terdapat beberapa tahapan yang dilakukan. Identifikasi masalah, pemilihan data uji, proses input data uji kedalam sistem. Alur activity diagram terdapat pada Gambar 1.

Berdasarkan form Gambar 1, merupakan activity diagram dalam menjelaskan proses dan peran yang dilakukan oleh aktor dan juga sistem.

Proses selanjutnya dilakukan pengujian dengan menyiapkan beberapa data uji. Dari bentuk form yang akan diuji, sebagai contoh pengujian akan dilakukan pada dua field yaitu username dan password. 


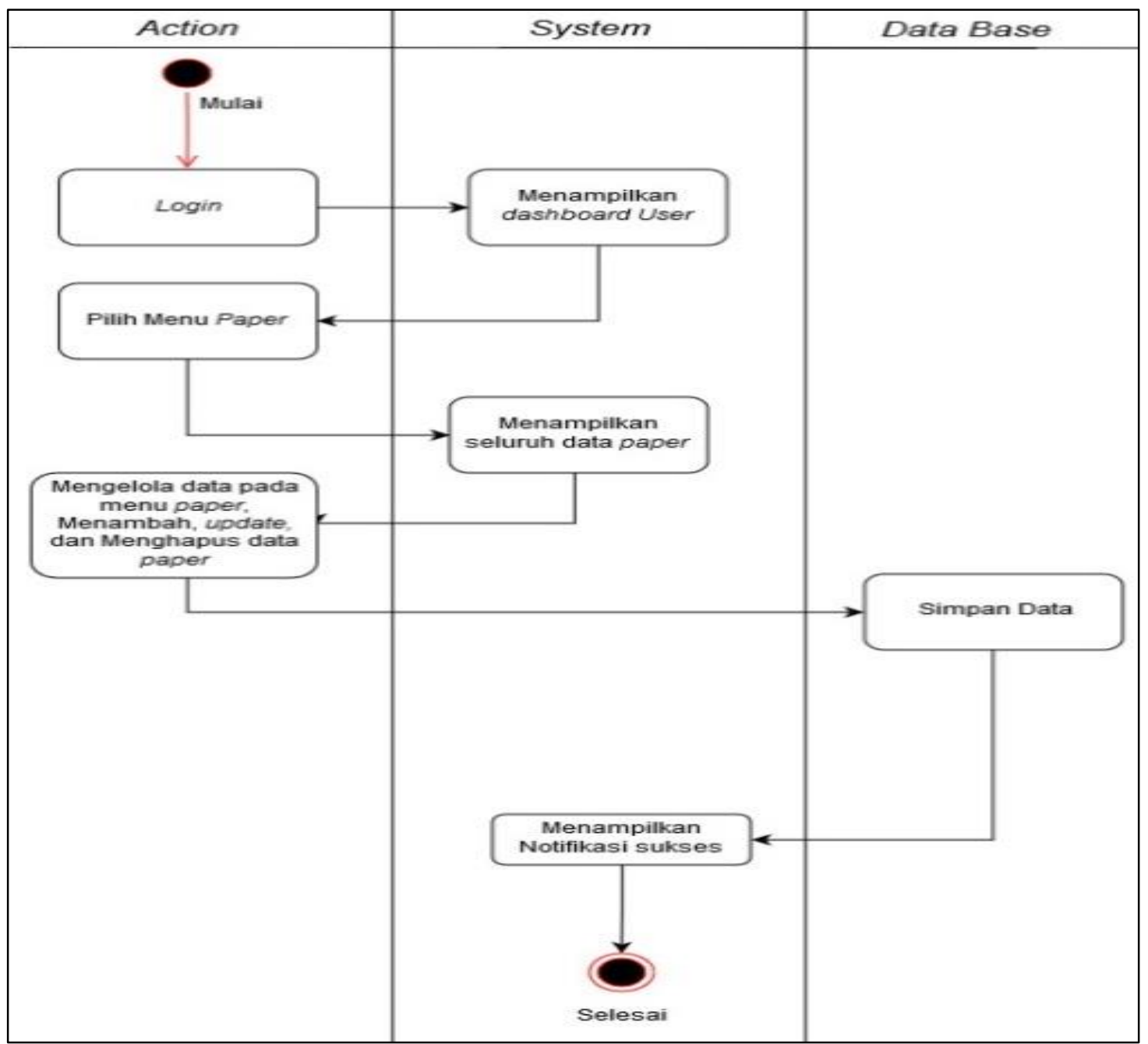

Gambar 1. Activity Diagram Tabel Paper

Tabel 1. Struktur Tabel Pengujian

\begin{tabular}{ccc}
\hline Nama Field & Type Data & Length \\
\hline Username & Varchar & 20 \\
Password & Varchar & 20 \\
\hline
\end{tabular}

Tabel 2. Hasil Uji Aturan A.1

\begin{tabular}{cccc}
\hline Contoh Data & $\begin{array}{c}\text { Hasil Pengujian yang } \\
\text { Diharapkan }\end{array}$ & Hasil Pengujian & $\begin{array}{c}\text { Berhasil atau } \\
\text { Tidak Berhasil }\end{array}$ \\
\hline User@email.co.id & $\mathrm{F}$ & $\mathrm{T}$ & Tidak Berhasil \\
User@email.com & $\mathrm{T}$ & $\mathrm{T}$ & Berhasil \\
User & $\mathrm{F}$ & $\mathrm{F}$ & Berhasil \\
User123@email & $\mathrm{F}$ & $\mathrm{F}$ & Berhasil \\
\hline
\end{tabular}

Tabel 1 menunjukkan tabel basis data sebenarnya dari view login. Tabel 1 menjadi acuan untuk melakukan pengujian dengan batasan tipe data dan panjang tipe data dari masing-masing field yang harus dipenuhi. 
Pengujian Field 1

Aturan entri data A.1: harus mencantumkan@email.com.

Dari hasil pengujian yang dilakukan (sesuai pada Tabel 2), terdapat empat kali uji coba contoh data, dimana hasil pengujian yang diharapkan ada nilai boolean True (T) dan ada False (F). Setelah dibandingkan dengan hasil pengujian sesungguhnya, maka diperoleh hasil 1 kali hasil pengujian yang tidak tepat dengan apa yang diharapkan atau dengan kata lain dapat dikatakan terjadinya 'error' untuk pengujian entri data A.1. Sehingga tingkat kebenaran pada aksi ini berkisar $75 \%$.

\section{Aturan entri data A.2: Kata pada password minimal 4 huruf}

Berdasarkan hasil uji pada suatu form di atas dapat disiapkan beberapa kasus data uji. Pada contoh di Tabel 3, terdapat dua field yang akan diuji, dengan masing-masing field memuat minimal 2 aturan uji (Fatiyah, Gumilang, \& Deden,
2019). Untuk satu aturan uji, perlu disiapkan minimal 3 data uji, sehingga total data uji yang perlu disiapkan untuk kasus di atas adalah 2 field $\mathrm{x} 2$ aturan $\mathrm{x} 3$ data uji yaitu 12 data uji (Zuriati et al, 2018). Hal ini dapat memberikan gambaran jumlah data uji yang harus disiapkan untuk melakukan black box testing dengan metode BVA. Hasil pengujian memperlihatkan bahwa aplikasi ini masih memiliki beberapa kekurangan yaitu belum lengkapnya proses validasi data sehingga masih perlu penyempurnaan dengan menambah fungsi validasi.

\section{Pengujian Field 2}

Pengujian pada penelitian berikut akan dilakukan pada submission system fungsi tabel input paper. Pada tahapan pengujian tabel paper memiliki beberapa field yang diuji, seperti yang ditunjukkan pada Tabel 4. Pada setiap field memiliki batasan-batasan tertentu dan sesuai dengan length yang telah ditentukan.

Tabel 4. Struktur Tabel Paper

\begin{tabular}{ccc}
\hline Nama Field & Tipe Data & Length \\
\hline ID & BigInt & 20 \\
Paperuid & Varchar & 191 \\
Code & Varchar & 191 \\
User_id & BigInt & 20 \\
Title & Varchar & 191 \\
Topic_Id & Int & 10 \\
Keywords & Varchar & 255 \\
Abstract & Varchar & 255 \\
Remarks & Text & - \\
Feedback & Text & - \\
Paper_file_id & BigInt & 20 \\
Poster_file_id & BigInt & 20 \\
Paper_file_feedback_id & BigInt & 20 \\
Poster_file_feedback_id & BigInt & 20 \\
Reviewer_id & BigInt & 20 \\
Created_by & Varchar & 191 \\
Createrd_at & TimeStamp & - \\
Update_at & TimeStamp & - \\
\hline
\end{tabular}


Tabel 5. Hasil Uji ID

\begin{tabular}{cccc}
\hline Contoh Data & $\begin{array}{c}\text { Hasil Pengujian } \\
\text { yang Diharapkan }\end{array}$ & $\begin{array}{c}\text { Hasil } \\
\text { Pengujian }\end{array}$ & $\begin{array}{c}\text { Berhasil atau } \\
\text { Tidak Berhasil }\end{array}$ \\
\hline 000002 & $\mathrm{~T}$ & $\mathrm{~T}$ & Berhasil \\
002 & $\mathrm{~T}$ & $\mathrm{~T}$ & Berhasil \\
000000000000000000002 & $\mathrm{~F}$ & $\mathrm{~F}$ & Berhasil \\
00000000002 & $\mathrm{~T}$ & $\mathrm{~T}$ & Berhasil \\
\hline
\end{tabular}

Tabel 6. Hasil Uji paperuid

\begin{tabular}{cccc}
\hline Contoh Data & $\begin{array}{c}\text { Hasil Pengujian yang } \\
\text { Diharapkan }\end{array}$ & $\begin{array}{c}\text { Hasil } \\
\text { Pengujian }\end{array}$ & $\begin{array}{c}\text { Berhasil atau } \\
\text { Tidak Berhasil }\end{array}$ \\
\hline PID-2019000001 & T & T & Berhasil \\
2019000001 & F & F & Berhasil \\
PID-01 & F & F & Berhasil \\
PID-201900002 & F & T & Tidak Berhasil \\
\hline
\end{tabular}

Tabel 7. Hasil Uji title

\begin{tabular}{cccc}
\hline Contoh Data & $\begin{array}{c}\text { Hasil Pengujian } \\
\text { yang Diharapkan }\end{array}$ & $\begin{array}{c}\text { Hasil } \\
\text { Pengujian }\end{array}$ & $\begin{array}{c}\text { Berhasil atau } \\
\text { Tidak Berhasil }\end{array}$ \\
\hline $\begin{array}{c}\text { Pembuatan Sistem Kamus } \\
\text { Bahasa Jawa Tengah Berbasis }\end{array}$ & $\mathrm{T}$ & $\mathrm{T}$ & Berhasil \\
Android & $\mathrm{F}$ & $\mathrm{F}$ & Berhasil \\
Matematika & $\mathrm{T}$ & $\mathrm{T}$ & Berhasil \\
Bahasa Sunda & $\mathrm{T}$ & $\mathrm{T}$ & Berhasil \\
\hline
\end{tabular}

Dari hasil pengujian yang dilakukan (sesuai pada Tabel 5), terdapat empat kali uji coba contoh data, dimana hasil pengujian yang diharapkan ada nilai boolean True (T) dan ada False (F). Setelah dibandingkan dengan hasil pengujian sesungguhnya, maka diperoleh hasil pengujian yang tepat dengan apa yang diharapkan atau dengan kata lain tidak terdapat 'error' untuk pengujian entri sesuai pada Tabel 5. Sehingga tingkat kebenaran pada aksi ini berkisar $100 \%$.

Dari hasil pengujian yang dilakukan (sesuai pada Tabel 6), terdapat empat kali uji coba contoh data, dimana hasil pengujian yang diharapkan ada nilai boolean True (T) dan ada False (F). Setelah dibandingkan dengan hasil pengujian sesungguhnya, maka diperoleh hasil 1 kali hasil pengujian yang tidak tepat dengan apa yang diharapkan atau dengan kata lain dapat dikatakan terjadinya 'error' untuk pengujian entri data sesuai pada Tabel 6. Sehingga tingkat kebenaran pada aksi ini berkisar $75 \%$.

Dari hasil pengujian yang dilakukan (sesuai pada Tabel 7), terdapat empat kali uji coba contoh data, dimana hasil pengujian yang diharapkan ada nilai boolean True $(\mathrm{T})$ dan ada False $(\mathrm{F})$. Setelah dibandingkan dengan hasil pengujian sesungguhnya, maka diperoleh hasil pengujian yang tepat dengan apa yang diharapkan atau dengan kata lain tidak terdapat 'error' untuk pengujian entri sesuai pada Tabel 7. Sehingga tingkat kebenaran pada aksi ini berkisar $100 \%$. 
Tabel 8. Hasil Uji abstract

\begin{tabular}{cccc} 
Contoh Data & $\begin{array}{c}\text { Hasil } \\
\text { Pengujian } \\
\text { yang } \\
\text { Diharapkan }\end{array}$ & $\begin{array}{c}\text { Hasil } \\
\text { Pengujian }\end{array}$ & $\begin{array}{c}\text { Berhasil atau } \\
\text { Tidak Berhasil }\end{array}$ \\
\hline $\begin{array}{c}\text { Permasalahan yang terjadi } \\
\text { merupakan penelitian yang telah } \\
\text { dilakukan sebelumnya pada tahun } \\
2015\end{array}$ & $\mathrm{~T}$ & $\mathrm{~T}$ & Berhasil \\
$\begin{array}{c}\text { Penelitian ini berdasarkan metode } \\
\text { matematika (Uji 1) }\end{array}$ & $\mathrm{T}$ & $\mathrm{T}$ & Berhasil \\
$\begin{array}{c}\text { Penelitian ini berdasarkan metode } \\
\text { matematika (Uji 2) }\end{array}$ & $\mathrm{F}$ & $\mathrm{F}$ & Berhasil \\
Matematika & $\mathrm{F}$ & $\mathrm{T}$ & Tidak Berhasil \\
\hline
\end{tabular}

Dari hasil pengujian yang dilakukan (sesuai pada Tabel 8), terdapat empat kali uji coba contoh data, dimana hasil pengujian yang diharapkan ada nilai boolean True (T) dan ada False (F). Setelah dibandingkan dengan hasil pengujian sesungguhnya, maka diperoleh hasil 1 kali hasil pengujian yang tidak tepat dengan apa yang diharapkan atau dengan kata lain dapat dikatakan terjadinya 'error' untuk pengujian entri data sesuai pada Tabel 8. Sehingga tingkat kebenaran pada aksi ini berkisar $75 \%$.

Pengujian yang dilakukan tidak diterapkan pada topic, input paper dan input poster, karena fungsi tersebut berupa dropbox yang sudah tersedia isinya dan data input berupa file dengan ukuran maksimal 15 Megabyte.

\section{KESIMPULAN}

Pada metodologi pemrograman modular yang diterapkan pada submission system, Black Box Testing memainkan peran penting. Black Box Testing, juga dikenal sebagai pengujian dinamis, adalah jenis pengujian dimana perilaku dan kerja perangkat lunak diuji dengan memeriksa input dan output perangkat lunak. Penelitian ini telah melakukan pengujian pada fungsionalitas submission system dengan menggunakan metode pengujian Black Box Testing Boundary Value Analysis dapat ditarik kesimpulan bahwa:

1. Metode Black Box Testing merupakan salah satu metode yang mudah untuk digunakan karena hanya memerlukan batas bawah dan batas atas dari data yang diharapkan. Akan tetapi tidak dapat mengidentifikasi bug dalam struktur internal.

2. Estimasi banyaknya data uji dapat dihitung melalui banyaknya field data entri yang akan diuji, aturan entri yang harus dipenuhi serta kasus batas atas dan batas bawah yang memenuhi.

3. Setelah melakukan pengujian diketahui bahwa fungsionalitas masih bisa berjalan namun masih dapat menerima masukan data yang tidak diharapkan sehingga menyebabkan data yang disimpan kurang valid.

4. Berdasarkan hasil uji dengan metode BVA maka fungsi entri data perlu dilengkapi dengan beberapa proses validasi data untuk menjamin akurasi entri dua sesuai fungsional yang diinginkan. 
DAFTAR PUSTAKA

Anardani, S., \& Putera, A. R. (2019). Analisis Pengujian Sistem Informasi Website E-Commerce Manies Group Menggunakan Metode BlackBox Functional Testing. Seminar Nasional Hasil Penelitian dan Pengabdian kepada Masyarakat UNIPMA (pp. 72-75). Madiun: LPPM Universitas PGRI Madiun.

Ardana, I. S. (2019). Pengujian Software Menggunakan Metode Boundary Value Analysis dan Decision Table Testing. Jurnal Teknologi Informasi ESIT.14(3): 40-47.

Fatiyah, A. C., Gumilang, S. F., \& Deden, W. (2019). Pengujian Fungsional dan Non Fungsional Aplikasi Web Borongjayuk. e-Proceeding of Engineering (pp. 8415-8421). Telkom University.

Hidayat, T., \& Putri, H. D. (2019) Pengujian Portal Mahasiswa pada Sistem Informasi Akademik (SINA) menggunakan Black Box Testing dengan Metode Equivalence Partitioning dan Boundary Value Analysis. JUTIS. 7(1): 83-92.

Jaya, T. S. (2018). Pengujian Aplikasi dengan Metode Blackbox Testing Boundary Value Analysis (Studi Kasus: Kantor Digital Politeknik Negeri Lampung). Jurnal Informatika: Jurnal Pengembangan IT (JPIT). 3(1): 4548.

Kartiko, C. (2019). Evaluasi Kualitas Aplikasi Web Pemantau Menggunakan Model Pengujian
Perangkat Lunak ISO/IEC 9126. JNTETI. 8(1): 16-23.

Kartiko, C., \& Hertantyo, G. B. (2018). Peningkatan Kualitas Aplikasi Pemantau Media Sosial dan Media Daring Menggunakan Metode WebQEM. JNTETI. 7(2): 144-149.

Nurudin, M., Jayanti, W., Saputro, R. D., Saputra, M. P., \& Yulianti, Y. (2019). Pengujian Black Box pada Aplikasi Penjualan Berbasis Web Menggunakan Teknik Boundary Value Analysis. Jurnal Informatika Universitas Pamulang. 4(4): 143148.

Prasetio, Y. L., Hanafiah, N., Yosanny, A., Yolanda, C., Musbar, F. P., \& Septianto, D. Pengembangan (2014). Aplikasi Penjadwalan Wisata Harian Pada Smartphone dengan Pendekatan Scrum. Jurnal ComTech. 5(2): 534-543.

Stellman, A., \& Hart, J. A. Learning Agile: Understanding Scrum, XP, Lean, and Kanban 1st Edition. O'Reilly Media. 2013.

Sutanto, Y., Utomo, A., \& Perbawa, D. S. Pengujian Aplikasi Website Menggunakan Black Box Testing Boundary Value Analysis (Studi Kasus: Aplikasi Website Praktekdokter). Jurnal SAINSTECH Politeknik Indonusa Surakarta. 2018; 5(2): 52-57.

Zuriati, Z., Widyawati, D. K., Sitanggang, I. S., \& Buowo, A. (2018). Teknik Pengujian Boundary Value Analysis Pada Aplikasi Learning Management System Polinela. Jurnal TAM (Technology Acceptance Model). 9(2): 85-92. 